\title{
A Educação Ambiental no Ensino Fundamental: Um Panorama das Teses e Dissertações Brasileiras (2007 - 2016)
}

\section{Environmental Education in Basic Education: A Panorama of Brazilian Thesis and Dissertations (2007 - 2016)}

\author{
Márcia Belo Soares ${ }^{1}$; Rita de Cássia Frenedozo ${ }^{2}$ \\ 1 Mestre em Ensino de Ciências e Matemática e Doutoranda em Ensino de Ciências e Matemática pela Universidade \\ Cruzeiro do Sul (UNICSUL). São Paulo, São Paulo, Brasil - E-mail: belomarcia@yahoo.com.br/ ORCID \\ https://orcid.org/0000-0001-8067-6753 \\ 2 Professora Titular e Orientadora da Universidade Cruzeiro do Sul (UNICSUL). Doutora em Geociências e Meio Ambiente \\ pela Universidade Estadual Paulista Júlio de Mesquita Filho. São Paulo, São Paulo, Brasil - E-mail: \\ ritafrenedozo@yahoo.com.br /ORCID https://orcid.org/0000-0002-5005-677X
}

Recebido em 31/03/2018. Publicado em Agosto/2019

\section{Palavras-chave: \\ Educação Ambiental 1. Ensino Fundamental 2. Mapeamento 3. Teses e Dissertações 4.}

\section{Keywords:}

Environmental Education 1. Elementary School 2. Mapping 3. Thesis and Dissertations 4.
RESUMO: O artigo apresenta um panorama da produção acadêmica de como Educação Ambiental tem sido abordada no Ensino Fundamental nas produções brasileiras (teses e dissertações) desenvolvidas nos Programas de Pós-Graduação de Educação em Ensino no período entre 2007 a 2016. Foram selecionadas, lidas e analisadas 29 pesquisas que abrangem a temática ambiental no Ensino Fundamental. Para análise e interpretação dos dados, adotamos a técnica de Análise de Conteúdo. Os resultados mostram que a maioria das pesquisas são dissertações (27), com predomínio em programas de pós-graduação na área de Educação, sendo doze pesquisas de instituições públicas federais, seguidas por sete instituições privadas e quatro estaduais. As regiões que mais contribuíram com estudos foram Sudeste com doze e Sul com nove pesquisas. As análises dos dados revelaram que o Ensino Fundamental II (anos finais - $6^{\circ}$ ao $9^{\circ}$ ano) foi o nível de ensino que mais concentrou pesquisas (quinze) e apontou também que há uma carência da temática na Educação Infantil. Em relação ao público pesquisado, os professores foram os sujeitos que tiveram maior destaque nos estudos, apareceram em doze estudos. Identificamos que as Práticas Pedagógicas Docentes são as mais recorrentes nas produções analisadas sobre a temática ambiental, sendo encontradas em 21 trabalhos. A pesquisa aponta para uma carência dentro dos Programas de PósGraduação de Educação e Ensino sobre a temática ambiental no Ensino Fundamental e a necessidade da inserção da Educação Ambiental no Ensino Fundamental (Educação Básica) como um todo.

ABSTRACT: The article presents a panorama of the academic production of Environmental Education as it has been approached in Primary Education in Brazilian productions (thesis and dissertations) developped in the Graduate Programs of Education and Teaching in the period between 2007 and 2016. Twenty nine researches were selected, read and analyzed, covering the environmental theme in both Elementary and Junior High School. For analysis and interpretation of data, we adopted the Content Analysis technique. The results show that most of the researches are dissertations (27), with predominance in postgraduate programs in the Education area, being twelve surveys of federal public institutions, followed by seven in private 
and four in state institutions. The regions that most contributed with studies were Southeast with twelve and South with nine surveys. Data analysis revealed that Junior High School (final years - 6th to 9th grade) was the level of education that most concentrated research (fifteen) and also pointed out that there is a lack of the theme in Early Childhood Education. In relation to the public researched the teachers were the subjects that had more prominence in the studies, since they appeared in twelve. We identified that the Teaching Pedagogical Practices are the most recurrent in the analyzed productions on the environmental theme, being found in 21 papers. The research points to a lack within the Graduate Programs of Education and Teaching on the environmental theme in Elementary School and the need of the insertion of Environmental Education in Primary Education (Basic Education) as a whole.

\section{INTRODUÇÃO}

A temática ambiental segundo Dias (2010) começou a ganhar forças a partir de 1960; foram diversos os congressos, debates e conferências (nacionais e internacionais) que surgiram e trouxeram a discussão da crise ambiental enfatizando a ideia da Educação Ambiental (EA).

No contexto brasileiro, as discussões iniciaram em 1980. A Constituição Federal de 1988 (Cap. VI, art. 225, parágrafo 1, inciso VI) cita a obrigatoriedade da promoção da Educação Ambiental em todos os níveis de ensino (BRASIL, 1988).

A Conferência das Nações Unidas sobre o Meio Ambiente e Desenvolvimento - Rio92 - foi um marco na trajetória da EA. Em 2012, a Conferência Rio+20 objetivou a renovação dos compromissos para o desenvolvimento sustentável para as próximas décadas e apontou na agenda 21 a preocupação com as condições de sobrevivência futura no planeta.

Nos Parâmetros Curriculares Nacionais (PCNs) da Educação Básica, a EA deve ser incluída por meio do tema Meio Ambiente, de maneira contínua e interdisciplinar. O professor deve proporcionar momentos de reflexão e formação do pensamento crítico em relação à realidade vivenciada pelos estudantes (BRASIL, 1997).

Conforme a Lei $\mathrm{n}^{\circ} 9.795$, a EA deve "estar presente de maneira articulada nos diferentes níveis e modalidades do processo educativo, em caráter formal e não formal" (BRASIL, 1999, p.1).

Penteado (2000) cita que as disciplinas apresentadas nas escolas devem representar os recursos didáticos que colocam ao alcance dos alunos os conhecimentos científicos disponíveis à sociedade.

Portanto, cabe à escola contribuir para a formação de cidadãos críticos e participativos conscientes de sua atuação na sociedade.

Diante desse contexto, temos uma inquietação sobre a abordagem da temática ambiental no Ensino Fundamental (EF). Para tanto, realizamos um mapeamento das 
Ensino, Saúde e Ambiente - V12 (2), pp. 70-87, Ago. 2019

dissertações e teses produzidas em Programas de Pós-Graduação em Educação e Ensino e disponibilizadas na Biblioteca Digital de Teses e Dissertações da CAPES, defendidas e publicadas entre os anos de 2007 a 2016, visando trazer elementos para futuras análises e reflexões sobre o desenvolvimento acadêmico da área.

\section{FUNDAMENTAÇÃO TEÓRICA}

A EA é um campo em construção e deve ser desenvolvida no cotidiano dos que realizam o processo educativo. Ela deve ser abordada de forma interdisciplinar orientando a resolução de problemas locais (GUIMARÃES, 2015).

Sendo ela uma educação política que objetiva preparar o indivíduo para o exercício da cidadania, deve ser voltada para a sustentabilidade (BRASIL, 1999).

A EA segundo Loureiro (2011, p.73) é uma "práxis educativa e social que tem por finalidade a construção de valores, conceitos, habilidades e atitudes”.

Para Torzoni-Reis (2006) a EA é um processo permanente de aprendizagem baseado no respeito à vida e no estabelecimento de valores que contribuam para a transformação socioambiental e para a formação integral do ser humano.

A Política Nacional de Educação Ambiental - PNEA (1999) define a EA como sendo o processo no qual:

\footnotetext{
Os indivíduos e a coletividade constroem valores sociais, conhecimentos, habilidades, atividades e competências voltadas para a conservação do meio ambiente, bem de uso comum do povo, essencial à sadia qualidade de vida e sua sustentabilidade (BRASIL, 1999, p. 01).
}

As Diretrizes Curriculares Nacionais para a EA reconhecem sua relevância e obrigatoriedade no âmbito da Educação Básica e Superior e seu papel transformador capaz de promover a ética e a cidadania ambiental (BRASIL, 2012).

A EA ainda que não tenha um conceito único definido, a evolução dos conceitos, conforme Dias (2001), está diretamente relacionada à evolução dos conceitos de meio ambiente e ao modo como este é percebido pelo sujeito.

Neste sentido, alguns autores apontam que são as concepções que cada indivíduo tem sobre o ambiente que direcionam suas práticas pedagógicas utilizadas em sala de aula (SAUVÉ, 2005; GUIMARÃES, 2015; REIGOTA, 2015).

São diversas as propostas para a categorização das diferentes correntes identificadas nas práticas de EA: Sauvé (1997) apresenta 6 (seis) concepções tipológicas sobre o Ambiente na EA, são elas: como Natureza; Recurso; Problema; Lugar para Viver; Biosfera e Projeto Comunitário. O quadro 1 apresenta as diferentes concepções propostas pela autora. 
Ensino, Saúde e Ambiente - V12 (2), pp. 70-87, Ago. 2019

Quadro 1 - Tipologia das Concepções sobre o Ambiente na EA

\begin{tabular}{|l|l|l|}
\hline Ambiente & Relação & Características \\
\hline Como Natureza & Para ser apreciado e preservado & $\begin{array}{l}\text { Natureza como catedral, ou } \\
\text { como um útero, pura e original }\end{array}$ \\
\hline Como Recurso & Para ser gerenciado & $\begin{array}{l}\text { Herança bio física coletiva, } \\
\text { qualidade de vida }\end{array}$ \\
\hline Como Problema & Para ser resolvido & $\begin{array}{l}\text { Enfase na poluição } \\
\text { deterionização e ameaças }\end{array}$ \\
\hline Como Lugarpara Viver & $\begin{array}{l}\text { EA para, sobre e no para cuidar } \\
\text { do ambiente }\end{array}$ & $\begin{array}{l}\text { A natureza com os seus } \\
\text { componentes sociais, histónicos } \\
\text { e tecnológicos }\end{array}$ \\
\hline Como Biosfera & Como lugar para ser dividido & $\begin{array}{l}\text { Espaçonave Terra "Gaia", a } \\
\text { interdependência dos seres } \\
\text { vivos com os inanimados }\end{array}$ \\
\hline Como Projeto Comunitánio & Para ser envolvido & $\begin{array}{l}\text { A natureza como foco na } \\
\text { análise crítica na participação }\end{array}$ \\
\hline
\end{tabular}

Fonte: Sauvé (1997)

Podemos observar a influência dessas diferentes concepções nas práticas pedagógicas utilizadas pelos professores para o ensino da EA. Sauvé (2005) aponta que muitas vezes não são consideradas as inter-relações sujeitos-sociedade-natureza.

No cenário social atual a EA pode vir a se constituir como um possível recurso de transformação da realidade. E dentro desse cenário se coloca a questão: como a EA vem sendo trabalhada no EF?

\section{METODOLOGIA}

A presente pesquisa faz parte da nossa Tese de Doutorado em Ensino de Ciências e Matemática que se encontra em desenvolvimento. Ela é de caráter bibliográfico do tipo "Estado do Conhecimento" ou "Estado da Arte" e teve como objetivo mapear, avaliar e divulgar as produções acadêmicas. Tais pesquisas apresentam resultados e informações de outras pesquisas possibilitando conhecer e analisar as potencialidades e limitações de tais produções e criam novos caminhos para entender sobre determinado assunto (ROMANOWSKI; ENS, 2006).

As pesquisas do tipo "Estado do Conhecimento" ou "Estado da Arte" representam uma importante contribuição no processo de evolução da ciência de uma determinada área (ou tema) de conhecimento, pois elas buscam:

[...] identificar os aportes significativos da construção da teoria e prática pedagógica, apontar as restrições sobre o campo em que se move a pesquisa, as suas lacunas de disseminação, identificar experiências inovadoras investigadas que apontem alternativas de solução para os problemas da prática e reconhecer as contribuições da pesquisa na constituição de propostas na área focalizada (ROMANOWSKI; ENS, 2006, p. 39).

Nesse sentido, nossa pesquisa objetivou apresentar um panorama das produções acadêmicas que tiveram como foco a EA no EF, visando conhecer e analisar como essa temática está sendo abordada nesse nível de ensino. 
O mapeamento teve como propósito evidenciar as tendências e enfoques dessas produções, a partir da categorização e sistematização dos dados analisados, proporcionando uma visão do cenário dessa temática de pesquisa nos últimos 10 anos (2007 a 2016) e encontrou 29 produções acadêmicas com as características procuradas.

A proposta metodológica utilizada foi a Análise de Conteúdo, que segundo Bardin (2011), trata-se de:

Um conjunto de técnicas de análise das comunicações visando obter, por procedimentos sistemáticos e objetivos de descrição do conteúdo das mensagens, indicadores (quantitativos ou não) que permitam a inferência de conhecimentos relativos às condições de produção/recepção (variáveis inferidas) destas mensagens (BARDIN, 2011, p.47).

As três etapas da Análise de Conteúdo propostas por Bardin (2011) são: Pré-análise que compreende duas fases (a preparação do material e a leitura flutuante); Exploração do material que visa à escolha da Unidade de Registro e Escolha das Categorias; e a terceira e última etapa Análise dos Dados que compreende o tratamento dos resultados, inferência e interpretação. A seguir apresentaremos as referidas etapas:

\section{1 a ETAPA - PRÉ-ANÁLISE}

O Banco de Teses Dissertações faz parte do Portal de Periódicos da CAPES/MEC e tem como objetivo reunir e proporcionar a divulgação digital das teses e dissertações produzidas pelos programas de doutorado e mestrado reconhecidos em todo o país. O acesso ao banco digital ocorreu entre os meses de agosto e setembro de 2017.

A escolha dos trabalhos nos Programas de Pós-Graduação em Educação e Ensino do Banco de Teses e Dissertações da CAPES, do período entre 2007 a 2016, foi realizada por meio dos descritos presentes no título, palavras-chave e resumo.

Foram utilizados 7 (sete) descritores, o maior número de palavras-chave para as buscas sobre a temática, obedecendo assim as regras de exaustividade, representatividade e pertinência propostas por Bardin (2011). Os descritores utilizados foram: "Educação Ambiental no Ensino Fundamental"; "Educação Ambiental na Educação Básica"; "Ensino Fundamental e Educação Ambiental"; "Educação Ambiental Ensino Básico"; "Ensino Fundamental Anos Iniciais"; "Ensino Básico Educação Ambiental” e "Educação Ambiental Anos Iniciais".

No levantamento inicial foram encontrados 75 trabalhos (70 Dissertações e 5 Teses), sendo que, 1 trabalho apareceu em dois descritores. Consideramos então, o total de 74 (setenta e quatro) trabalhos encontrados, que possuem em seu título, resumo ou palavraschave um dos descritores utilizados como critério de busca adotado na pesquisa. 
Em seguida, optamos por fazer um levantamento de todos os trabalhos (ano de defesa, título, autor, grau acadêmico, resumo, instituição, área de conhecimento e eixo temático) os quais foram organizados em um arquivo de planilha do Programa Excel.

A leitura flutuante teve a função de tornar mais precisas as impressões e orientações emergentes, facilitando, desse modo, a observação dos documentos pesquisados.

A partir das leituras, identificamos e confirmamos os trabalhos que tinham relação com a temática ambiental no EF, realizamos leitura dos resumos, palavras-chaves, índices, introdução e de alguns capítulos que se fizeram necessários. Assim, seguindo estes passos constituímos o corpus da nossa pesquisa, a delimitação do material a ser analisado.

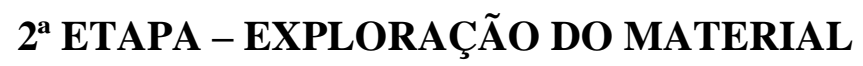

Após a pré-análise e exploração dos trabalhos selecionados, foram catalogados 29 trabalhos, sendo 2 (duas) teses e 27 (vinte e sete) dissertações, que tratam da EA no EF, distribuídos em 23 instituições, sendo 16 públicas (12 federais, seguidas por 4 estaduais) e 7 instituições privadas, conforme quadro 2.

Os títulos e dados autorais dessas teses e dissertações identificadas e catalogadas nesta pesquisa encontram-se relacionados no Anexo 1 deste artigo.

Quadro 2: Quantitativo de Teses e Dissertações selecionadas e suas respectivas Instituições

\begin{tabular}{|c|c|c|c|}
\hline \multicolumn{2}{|r|}{ Instituição } & \multirow{2}{*}{$\begin{array}{c}\text { Dissertação } \\
1\end{array}$} & \multirow[t]{2}{*}{ Tese } \\
\hline \multirow{12}{*}{ Federal } & Fundação Universidade Federal de Sergipe - UFS & & \\
\hline & Instituto Fed. de Educ., Ciência e Tec. do Rio de Janeiro - IFRJ & 1 & \\
\hline & Instituto Federal de Educação, Ciência e Tec. Espírito Santo-IFES & 1 & \\
\hline & Universidade de Brasilia - UnB & 1 & \\
\hline & Universidade Federal da Paraiba - UFPB & 1 & \\
\hline & Universidade Federal de Alagoas - UFAL & 1 & \\
\hline & Universidade Federal do Paraná - UFPR & 1 & \\
\hline & Universidade Federal do Rio Grande - FURG & 1 & \\
\hline & Universidade Federal do Rio Grande do Norte - UFRN & 1 & \\
\hline & Universidade Federal do Rio Grande do Sul - FURGS & 1 & \\
\hline & Universidade Federal Rural de Pernambuco - UFRPE & 2 & \\
\hline & Universidade Tecnológica Federal do Paraná - UTFPR & 2 & \\
\hline \multirow{4}{*}{ Estadual } & Universidade Estadual de Campinas - UNICAMP & 1 & 1 \\
\hline & Universidade Estadual de Londrina - UEL & 1 & \\
\hline & Universidade Estadual de Ponta Grossa - UEPG & 1 & \\
\hline & Univ. Estadual Paulista "Júlio de Mesquita Filho" UNESP Bauru & 1 & \\
\hline \multirow{7}{*}{ Privada } & Universidade Cruzeiro do Sul - UNICSUL & 2 & \\
\hline & Centro Universitário de Volta Redonda - UniFOA & 1 & \\
\hline & Centro Universitário Plínio Leite - UNIPLI & 1 & \\
\hline & Universidade Católica de Petrópolis - UCP & 2 & \\
\hline & Universidade Estácio de Sá-UNESA & 1 & \\
\hline & Universidade Luterana do Brasil - Canoas ULBRA & 2 & \\
\hline & Universidade Metodista de Piracicaba-UNIMEP & & 1 \\
\hline
\end{tabular}

Fonte: Elaborado pelas pesquisadoras 
A pesquisa identificou, conforme tabela 1, que foram poucos os trabalhos produzidos sobre a temática EA no EF, durante o período de 2007 a 2016. Apontamos, em especial, para um número pouco expressivo de trabalhos no ano de 2012, apenas duas dissertações, quando da realização da Rio+20 - Conferência das Nações Unidas sobre Desenvolvimento Sustentável, no Rio de Janeiro.

O número de trabalhos (seis) produzidos em 2014 pode ser em virtude do lançamento da $4^{\text {a }}$ Edição do Programa Nacional de Educação Ambiental - PRONEA que apresenta deliberações e Diretrizes Curriculares Nacionais da Educação Ambiental.

No entanto, embora, seja visível um discreto aumento na produção acadêmica sobre EA, percebe-se que pouco se avança no cenário da temática ambiental no nível de Ensino Fundamental.

Tabela 1 - Dissertações e Teses de 2007 a 2016

\begin{tabular}{c|c|c|c|c|c|c|c|c|c|c}
\hline Ano & 2007 & 2008 & 2009 & 2010 & 2011 & 2012 & 2013 & 2014 & 2015 & 2016 \\
\hline Tese & & & & & & & & & & 2 \\
\hline Dissertação & 1 & 1 & 5 & 2 & 1 & 2 & 2 & 6 & 2 & 5 \\
\hline TOTAL & 1 & 1 & 5 & 2 & 1 & 2 & 2 & 6 & 2 & 7 \\
\hline
\end{tabular}

Fonte: Elaborada pelas pesquisadoras

Tendo em vista o pequeno número de trabalhos (29) produzidos durante o período de 2007 a 2016, muito nos chamou atenção, pois após a Conferência da Rio-92 e a publicação, em 1997, dos PCN com o tema transversal Meio Ambiente, houve grande expansão da produção acadêmica nacional sobre EA de uma maneira geral (BRASIL, 1997).

Assim, retomamos nossa busca e constatamos que durante o mesmo período de 2007 a 2016 dentro dos Programas de Educação e Ensino do Banco da CAPES, foram apresentados 1.678 trabalhos desenvolvidos com a temática "Educação Ambiental”, conforme apresentado na tabela 2. Contudo, não observamos, no nosso levantamento, essa expansão da produção acadêmica sobre EA no EF.

Tabela 2 - "Educação Ambiental"

\begin{tabular}{c|c|c|c|c|c|c|c|c|c|c|c}
\hline Ano & 2007 & 2008 & 2009 & 2010 & 2011 & 2012 & 2013 & 2014 & 2015 & 2016 & TOTAL \\
\hline Trabalhos & 95 & 138 & 158 & 151 & 169 & 148 & 206 & 192 & 185 & 236 & 1678 \\
\hline
\end{tabular}

Fonte: Elaborada pelas pesquisadoras 
Nogueira (2016) em sua pesquisa cita que também se surpreendeu com os resultados encontrados, pois de um total de 2.763 teses e dissertações defendidas entre 1981 e 2012 no Banco do Projeto EArte (Estado da Arte da Pesquisa em Educação Ambiental), o qual representa um acervo da produção acadêmica e científica em teses e dissertações, produzidas no Brasil sobre EA, foram localizados apenas 21 trabalhos com a temática práticas interdisciplinares em EA na Educação Básica (Educação Infantil, Ensino Fundamental e Ensino Médio).

Após a pré-análise e exploração dos 29 trabalhos selecionados como corpus da pesquisa, realizamos releituras das produções selecionadas e seguimos para a fase de codificação do material e definição das categorias de análise.

A fase de categorização, cita Bardin (2011, p. 147), é uma “operação de classificação de elementos constituídos de um conjunto por diferenciação e, em seguida, por reagrupamento segundo o gênero (analogia), com os critérios previamente estabelecidos".

Seguindo os critérios já descritos, para análise e interpretação dos dados, agrupamos as informações em duas Unidades de Análise: Contexto e Enfoque das Pesquisas de onde emergiram 06 (seis) categorias, conforme descritas na figura 1:

Figura 1- Unidades de Análise e Categorias utilizadas no Mapeamento.

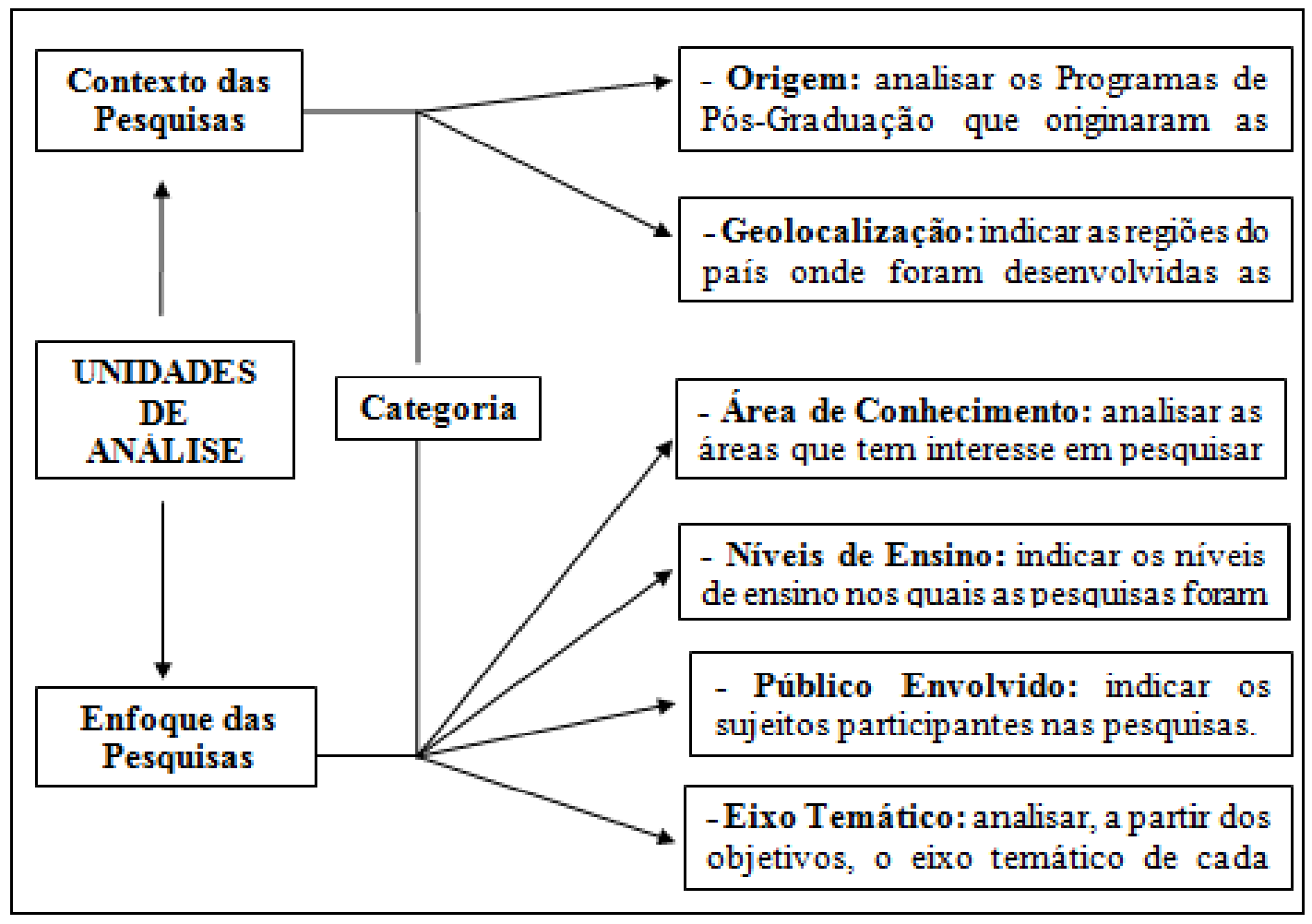

Fonte: Elaborada pelas pesquisadoras 


\section{RESULTADOS E DISCUSSÕES}

$\mathrm{Na} 3^{\mathrm{a}}$ Etapa apresentamos os resultados, inferência e interpretação a que chegamos nesta pesquisa e a maneira como eles foram tratados, buscamos transformar os resultados brutos, a fim de apresentar significados válidos, os quais foram apresentados em tabelas e gráficos simples, destacando as informações obtidas nas análises.

Portanto, tivemos como objetivo apresentar o panorama da produção acadêmica sobre EA no EF. Foram encontradas 29 produções acadêmicas que abordam a temática ambiental no nível de ensino fundamental, das quais 02 (duas) são teses e 27 (vinte e sete) são dissertações defendidas e publicadas no período entre 2007 a 2016, dentro do Programa de Pós-Graduação de Educação e Ensino disponibilizados no banco de teses da CAPES.

Os dados foram organizados e sistematizados, conforme figura 1, em duas Unidades de Análises: 1) Contexto das Pesquisas, constituída pelas categorias: Origem e Geolocalização e 2) Enfoque das Pesquisas, constituída pelas categorias: Área de Conhecimento; Níveis de Ensino; Público Envolvido e Eixo Temático.

Apresentamos a seguir os resultados da primeira Unidade de Análise: Contexto das Pesquisas, a qual foi composta por duas categorias Origem e Geolocalização dos trabalhos selecionados para esta pesquisa.

$\mathrm{Na}$ categoria Origem buscamos analisar os Programas de Pós-Graduação que originaram as pesquisas e que têm como contexto a EA no EF. Os Programas de PósGraduação em que as 29 produções acadêmicas têm sua origem na área de conhecimento da Educação e nos forneceram as constatações, apresentadas no gráfico 1.

Assim, analisando os percentuais, gráfico 1, evidencia-se a quantidade de treze pesquisas $(44,83 \%)$ oriundas dos Programas de Pós-Graduação em Educação, seguidas por cinco trabalhos $(17,22 \%)$ no Programa de Ensino de Ciências e Matemática, seis trabalhos (6,90\%), sendo dois trabalhos em cada um Programas: Ensino de Ciência e Tecnologia; Ensino de Ciências; Ensino de Ciências da Saúde e do Ambiente.

Os demais trabalhos foram divididos em cinco Programas, sendo cada um com uma única pesquisa (3,45\%), são eles: Educação Ambiental; Educação em Ciências e Matemática; Educação em Ciências Química da Vida e Saúde; Educação: Teoria e Prática de Ensino e Ensino de Ciências e Educação Matemática. 
Ensino, Saúde e Ambiente - V12 (2), pp. 70-87, Ago. 2019

Gráfico 1 - Programas de Pós-Graduação com pesquisas sobre Educação Ambiental no Ensino Fundamental

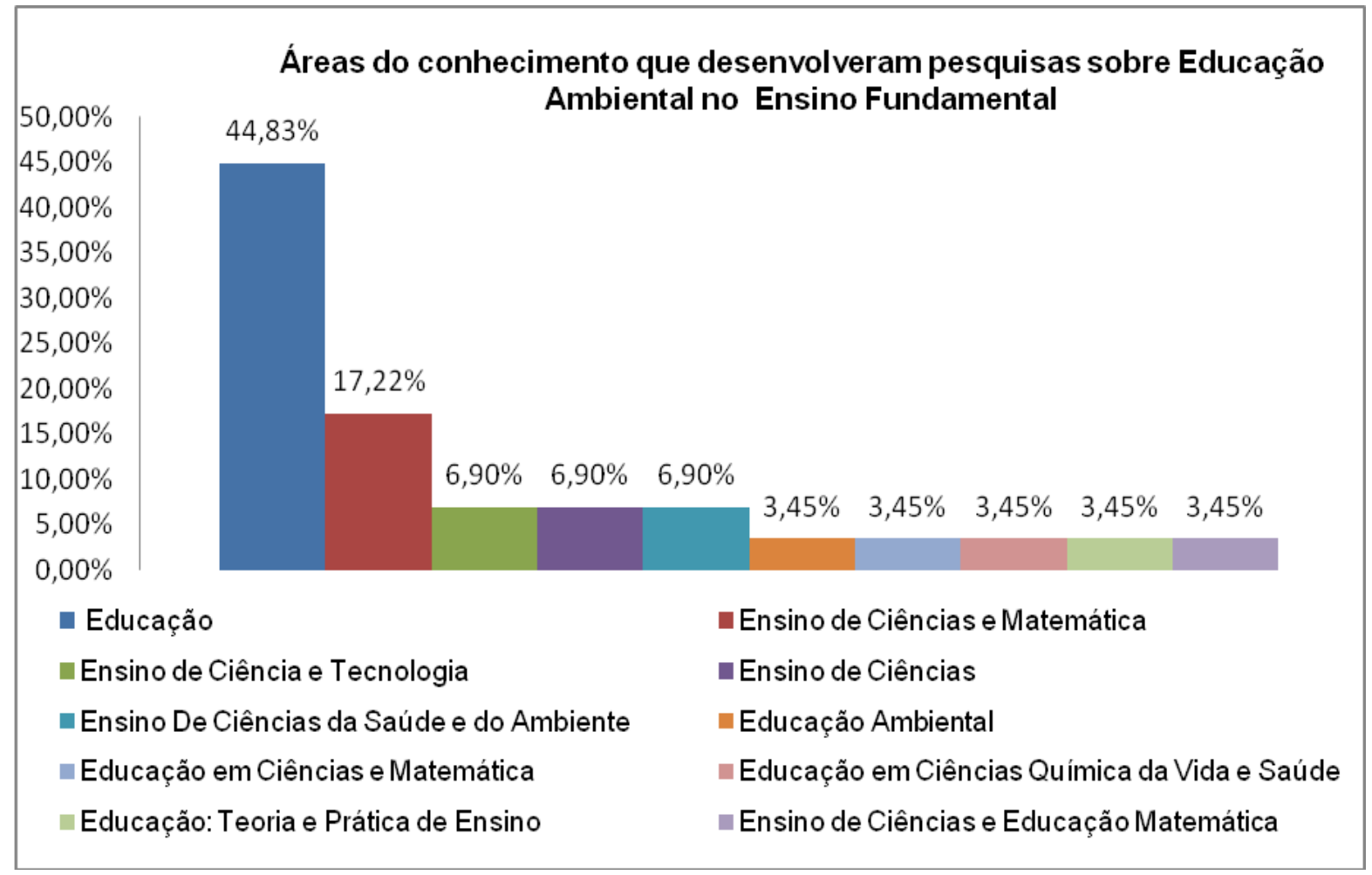

Fonte: Elaborado pelas pesquisadoras

Neste contexto, interpretamos que a diversidade de Programas de Pós-Graduação em que foram encontrados os trabalhos, evidencia uma rica possibilidade de produção de trabalhos envolvendo a temática ambiental.

Reigota (2007) cita que a pesquisa em EA a partir de 1980 vem se fortalecendo e que a temática começou a aparecer em teses e dissertações, sendo a primeira tese defendida por Luiz Marcelo de Carvalho (1989) na Universidade de São Paulo.

A consolidação da temática ambiental em pesquisas acadêmicas se deu entre a década de 1990 e o primeiro semestre do ano de 2000 nos diversos programas de pósgraduação (MEGID NETO, 2009).

Na segunda categoria Geolocalização, identificamos, gráfico 2, as regiões do país onde foram desenvolvidas as pesquisas realizadas durante o período de 2007 a 2016.

Observamos que os percentuais de produções desenvolvidas nas regiões Centro Oeste e Norte são equivalentes com uma pesquisa $(3,45 \%)$ em cada região; a região Nordeste apresentou seis pesquisas $(20,69 \%)$; as regiões que mais contribuíram foram Sul com nove $(31,03 \%)$, seguida pela região Sudeste com doze $(41,38 \%)$ pesquisas.

Os dados mostram que as pesquisas sobre EA no EF ainda estão concentradas nas instituições de ensino localizadas nas regiões Sudeste e Sul do Brasil. 
Ensino, Saúde e Ambiente - V12 (2), pp. 70-87, Ago. 2019

Gráfico 2 - Geolocalização das pesquisas por Região

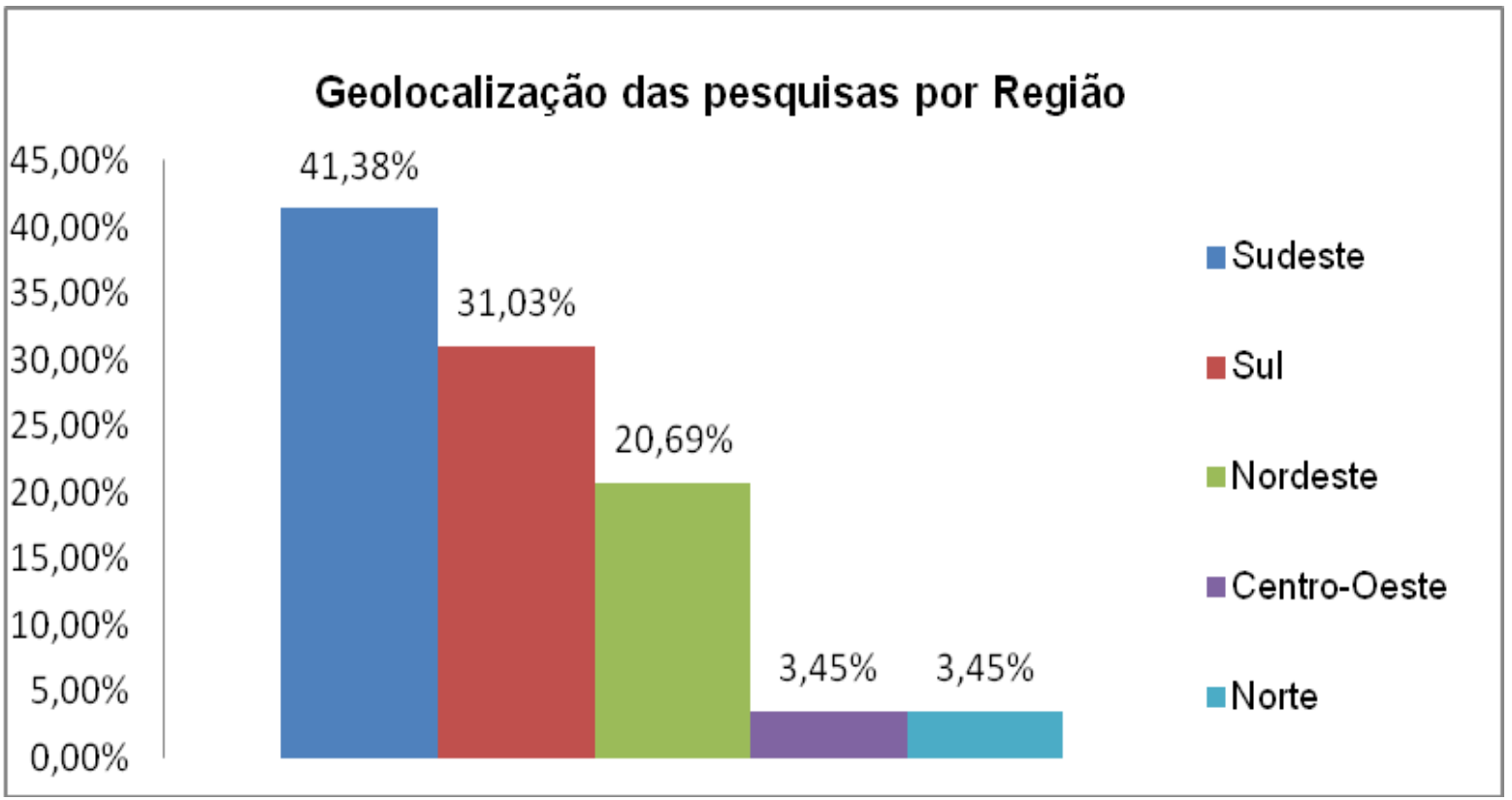

Fonte: Elaborado pelas pesquisadoras

Dias (2015) em sua pesquisa intitulada Práticas Pedagógicas de Educação Ambiental em Áreas Protegidas: um estudo a partir de dissertações e teses (1981-2009), também identificou maior concentração da produção acadêmica na Região Sudeste.

Ao comparar os percentuais dos trabalhos acadêmicos é possível apontar que essa distribuição desigual esteja relacionada com a quantidade de programas de Pós-Graduação existentes nas diferentes regiões.

Dentro da Unidade Temática Enfoque das Pesquisas emergiram quatro categorias, sendo elas: Área do Conhecimento; Nível de Ensino; Público Envolvido e Eixo Temático. A pesquisa apontou que são diversas as Áreas do Conhecimento que desenvolveram pesquisas sobre EA no EF.

Destacamos que, nos 29 trabalhos selecionados, a área da Educação é a que apresentou maior número (quinze) de trabalhos $(51,72 \%)$ desenvolvidos nos programas de Pós-Graduação, conforme gráfico 3. As demais áreas seguem assim divididas: área de Ensino de Ciências e Matemática com oito trabalhos (27,59\%), seguida pelas áreas de Ensino com cinco trabalhos $(17,24 \%)$ e a área de Ensino das Ciências com um trabalho (3,45\%). Podemos considerar que é observável o início do processo sobre a temática ambiental no EF. 
Ensino, Saúde e Ambiente - V12 (2), pp. 70-87, Ago. 2019

Gráfico 3 - Áreas do conhecimento que desenvolveram pesquisa sobre Educação Ambiental no Ensino Fundamental

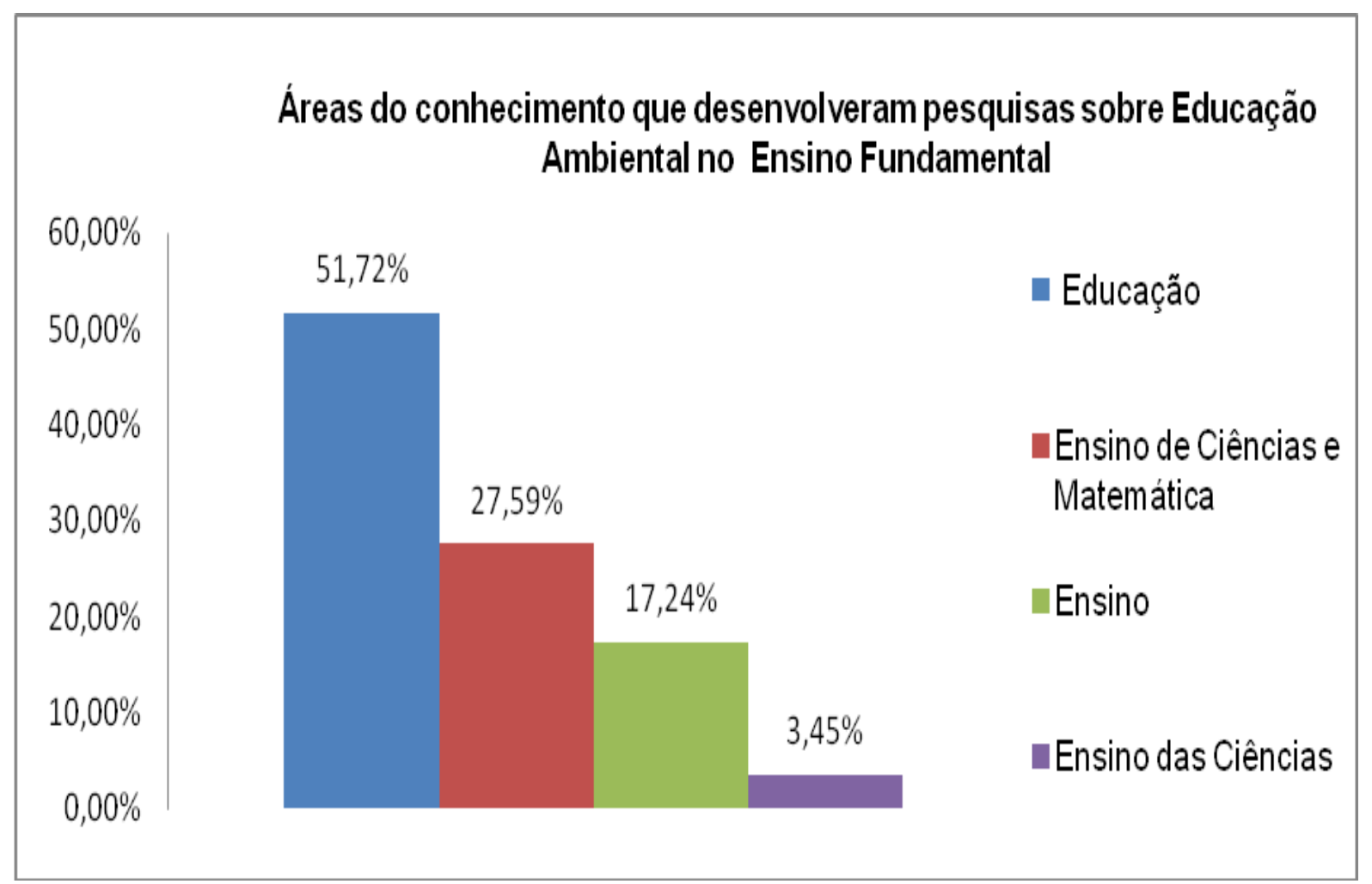

Fonte: Elaborado pelas pesquisadoras

Em sua pesquisa, Nogueira (2016) também destacou que a área da Educação foi a que mais apresentou trabalhos sobre a temática ambiental na Educação Básica.

Apontamos que os resultados estão relacionados diretamente com a origem das pesquisas dentro dos Programas de Pós-Graduação, pois conforme gráfico 1, foram identificadas $(44,83 \%)$ pesquisas com a temática ambiental no EF oriundas da área da Educação.

Em relação à Categoria denominada Níveis de Ensino os dados quantitativos (gráfico 4), apontam que nas teses e dissertações pesquisadas há uma predominância (quinze trabalhos - 51,72\%) de EA no EF II (anos finais - $6^{\circ}$ ao $9^{\circ}$ ano) e o EF I (anos iniciais - $1^{\circ}$ ao $5^{\circ}$ ano) é o segundo nível mais predominante com seis trabalhos $(20,70 \%)$ das pesquisas.

A pesquisa demonstrou também que foram cinco produções $(17,24 \%)$ realizadas com o EF, contudo, elas não especificam o nível de ensino (anos iniciais e/ou anos finais), sendo considerados então os dois níveis (EF I anos iniciais e EF II anos finais). A Educação Básica (Ensino Infantil, Ensino Fundamental e Médio) foi destaque em três trabalhos (10,34\%) da pesquisa. 
Ensino, Saúde e Ambiente - V12 (2), pp. 70-87, Ago. 2019

Gráfico 4 - Níveis de Ensino que desenvolvem pesquisa sobre Educação Ambiental no Ensino Fundamental

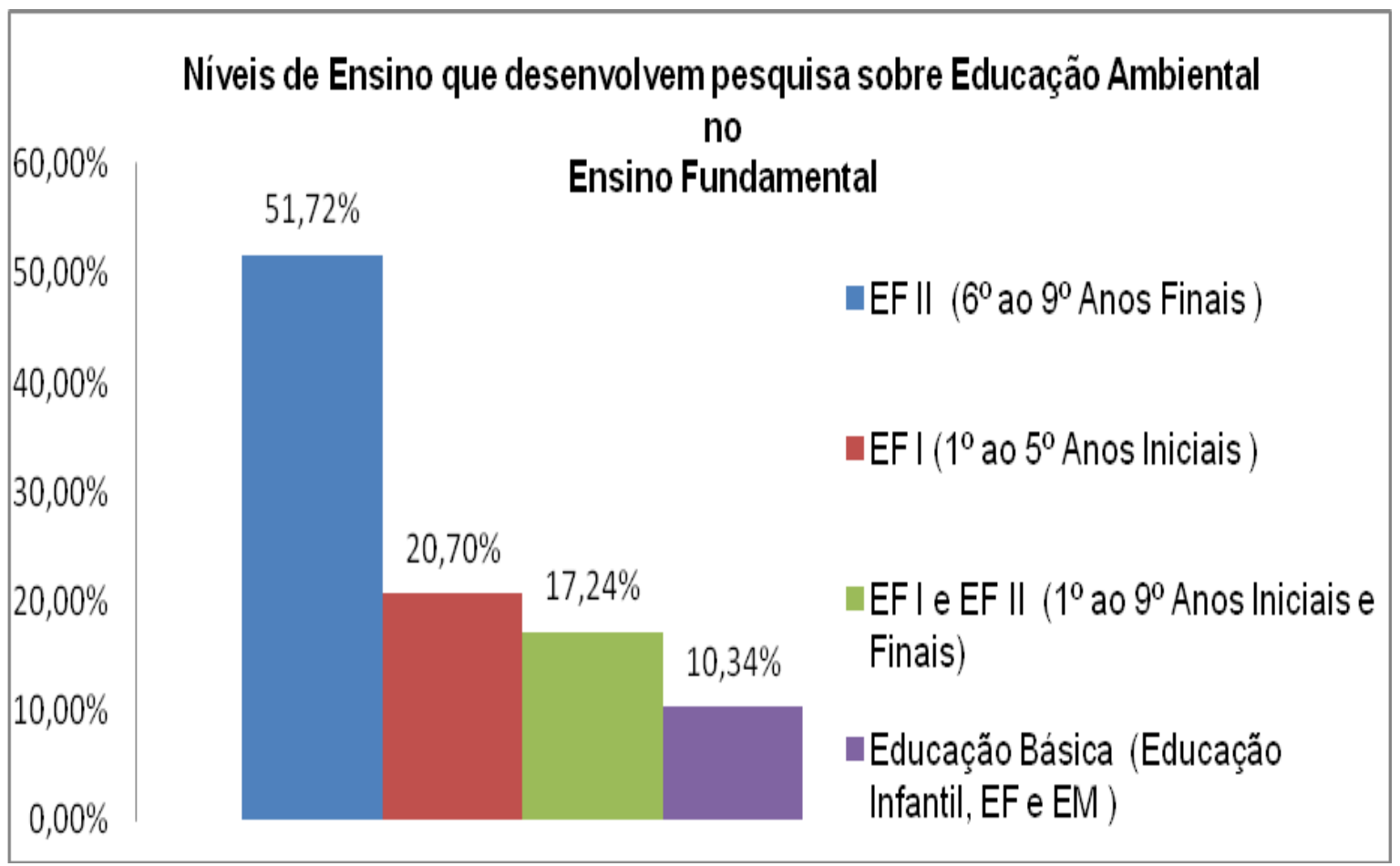

Fonte: Elaborado pelas pesquisadoras

Também foi destaque na pesquisa de Nogueira (2016) a concentração das ações no $\mathrm{EF}$, contudo nos anos iniciais, a pesquisadora cita que foram poucos os trabalhos com ações no ensino médio e nenhum estudo abrangeu a educação infantil.

Neste contexto, percebe-se a necessidade de intensificação de pesquisas voltadas para a temática ambiental na Educação Básica como um todo, não somente no EF. De acordo com os PCNs o tema Ambiental deve ser abordado como um tema transversal, devendo estar presente em todas as disciplinas de todas as séries da Educação Básica (BRASIL, 1998, p.197).

A categoria Público Envolvido apontou, conforme gráfico 5, que os Professores foram os sujeitos que tiveram maior destaque nas produções pesquisadas; foram doze trabalhos $(41,38 \%)$, seguidos de seis trabalhos $(20,69 \%)$ com estudantes e professores e também seis trabalhos realizados com estudantes. Os trabalhos realizados com gestores e professores totalizam quatro produções $(13,79 \%)$. Por fim, observa-se um número pequeno de trabalhos, apenas um $(3,45 \%)$, desenvolvido com Comunidade Escolar (professores, gestores, estudantes e famílias). 
Ensino, Saúde e Ambiente - V12 (2), pp. 70-87, Ago. 2019

Gráfico 5 - Público Envolvido nas pesquisas sobre Educação Ambiental no Ensino Fundamental

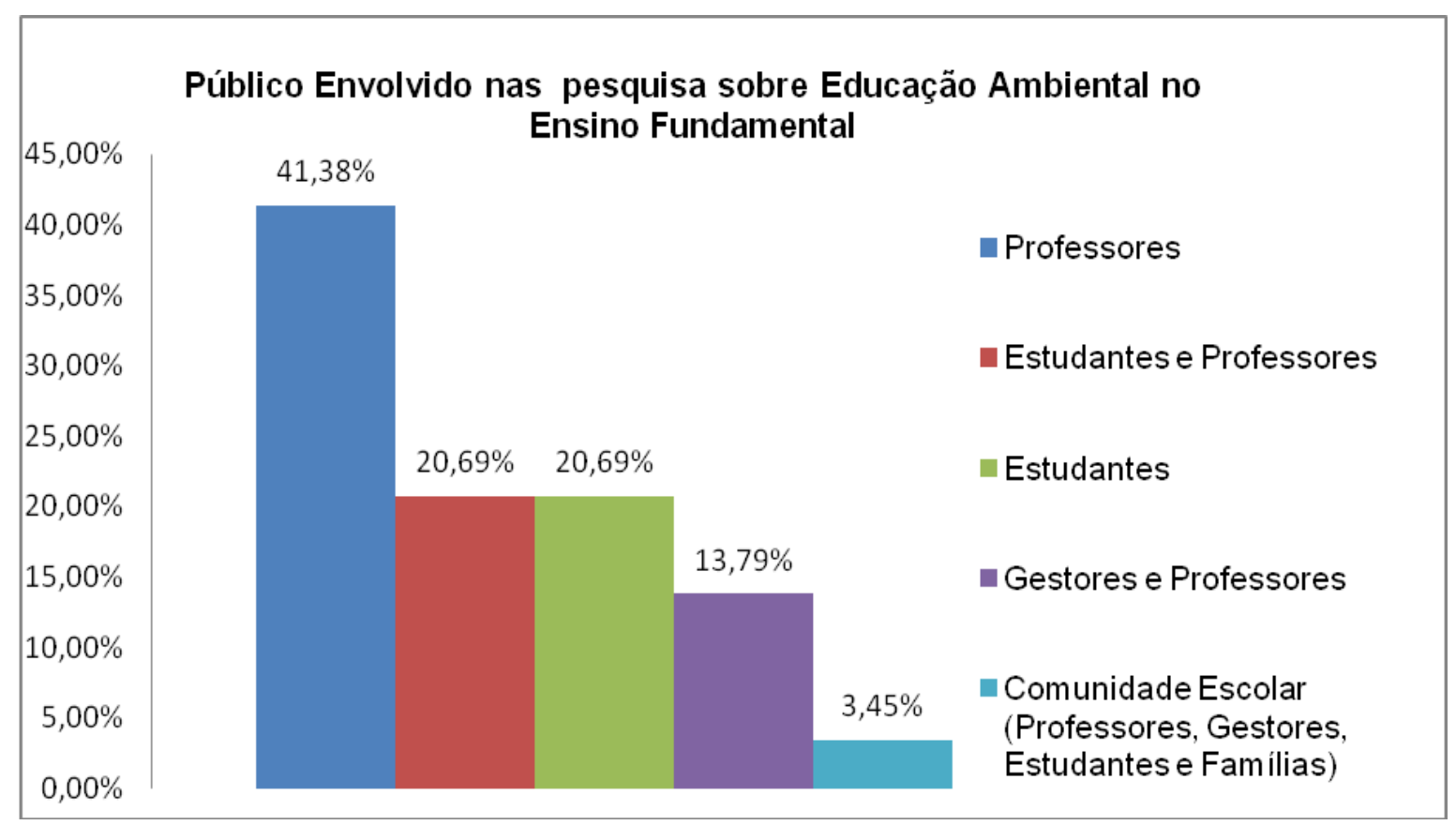

Fonte: Elaborado pelas pesquisadoras

Acreditamos que os resultados, apontados no gráfico 5, devem-se ao fato de que, embora tenhamos uma legislação específica que determina que a EA seja promovida em todos os níveis de ensino, cabe ao professor tornar a abordagem da temática ambiental uma realidade dentro do âmbito escolar (BRASIL, 1999).

Tendo em vista que, na categoria Eixo Temático alguns trabalhos apresentaram mais de um eixo temático, o resultado apresentará um número total de eixos temáticos maior que o número de pesquisa, conforme mostra o gráfico 6.

Apontamos que vinte e um trabalhos $(58,33 \%)$ têm seu eixo temático voltado para as Práticas Pedagógicas Docentes, Estratégias de Ensino e Métodos (Sequência Didática, Projetos e Atividades Lúdicas); seguidos de nove pesquisas (25\%) que abordam Concepções, Percepções e Representações. Também identificamos quatro trabalhos $(11,11 \%)$ voltados para estudos de Recursos e Materiais Didáticos. Os dados apontam, ainda, para um número pouco expressivo (dois trabalhos - 5,56\%) com enfoque nos Processos Formativos (Formação Inicial e Continuada).

Os resultados da pesquisa corroboram com os autores Travassos (2004), Reigota, (2007) e Guimarães (2015) quando enfatizam a importância e a necessidade de conhecer as concepções e/ou representações dos educadores sobre o ambiente, pois dependendo do que aceitamos como ambiente, nossas concepções poderão direcionar nossas práticas pedagógicas. 
Ensino, Saúde e Ambiente - V12 (2), pp. 70-87, Ago. 2019

Gráfico 6 - Eixo Temático das pesquisas sobre Educação Ambiental no Ensino Fundamental

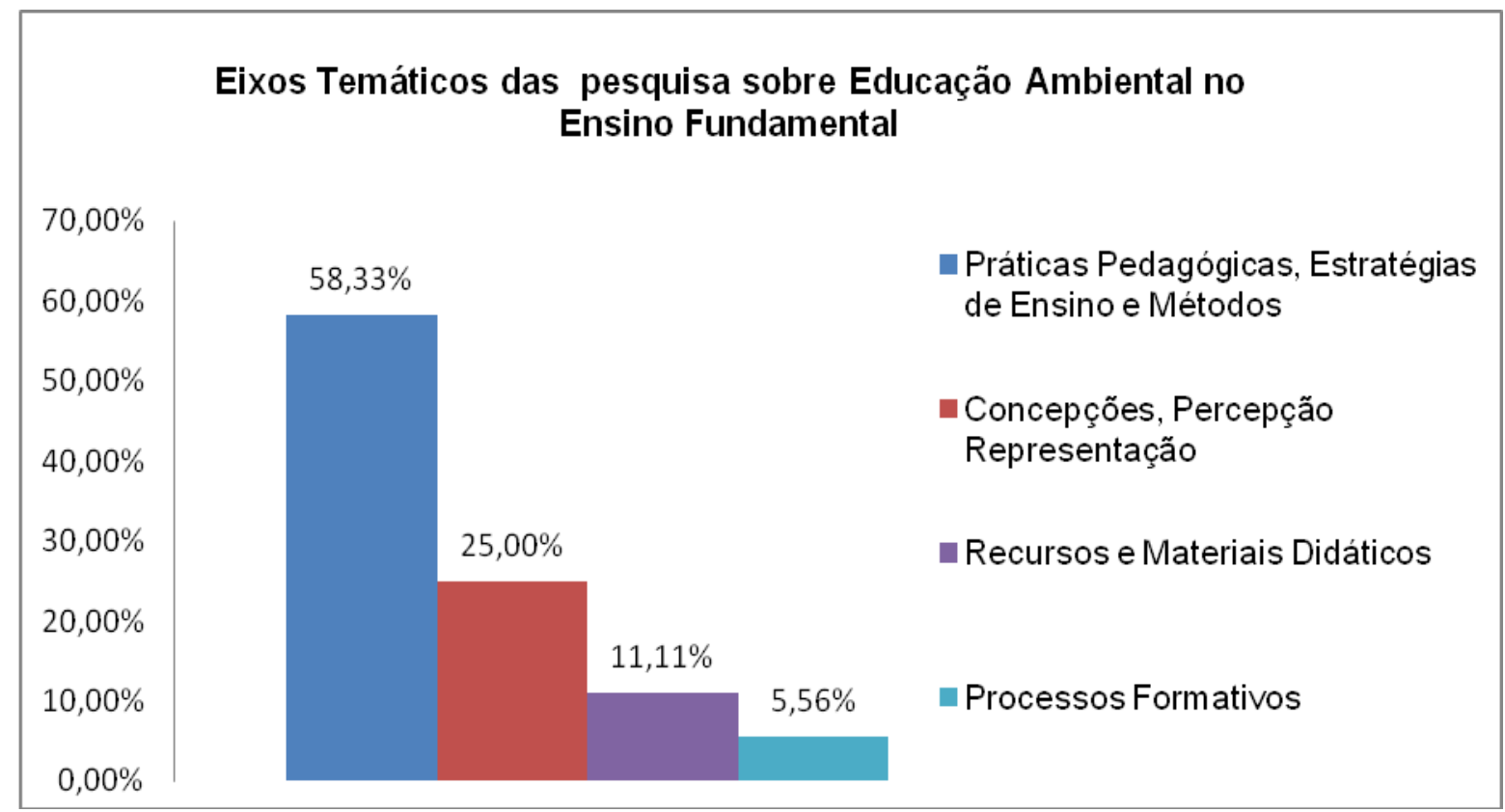

Fonte: Elaborado pelas pesquisadoras

Sato (2001) sinalizou para a carência da EA nos currículos de graduação, pósgraduação e cursos de formação continuada dentro do cenário nacional e em outros países latino-americanos.

A necessidade de investimento em formação continuada e de rever os cursos de formação inicial, a fim de preparar o educador para o trabalho com a temática ambiental, também foi revelada por Nogueira (2016) em sua pesquisa.

Guerra e Figueiredo (2015, p. 16) citam que a ambientalização curricular nas universidades é um processo contínuo, dinâmico e transversal que engloba "o currículo, a pesquisa, a extensão e a gestão ambiental" e ela deve ser debatida nas universidades objetivando a inserção da temática ambiental em todas as dimensões e nos diferentes níveis de ensino.

Neste contexto, mais do que conhecer as concepções e práticas dos educadores tornase fundamental proporcionar aos professores formação sobre a temática ambiental.

\section{CONSIDERAÇÕES FINAIS}

A pesquisa apontou um aumento no número de produções em EA, dentro dos Programas de Pós-Graduação de Educação e Ensino, conforme tabela 2, no entanto, este aumento não pode ser observado nas produções acadêmicas sobre a EA no EF, pois, encontramos apenas 29 trabalhos defendidos e publicados no banco de teses e dissertações da CAPES, no período entre 2007 a 2016. 
Ensino, Saúde e Ambiente - V12 (2), pp. 70-87, Ago. 2019

A temática ambiental no EF está concentrada nas regiões Sudeste e Sul com respectivamente doze e nove trabalhos. Os estudos permeiam as diversas áreas do conhecimento das vinte e três instituições de ensino dos Programas de Pós-Graduação de Educação em Ensino, sendo 16 públicas (doze federais, seguidas pelas quatro estaduais) e sete instituições privadas.

O estudo mostrou que os professores foram os sujeitos que tiveram maior destaque nas pesquisas aparecendo em doze estudos, seguidos por seis estudos realizados com estudantes e professores e também seis realizados com estudantes; os trabalhos com gestores e professores totalizam quatro produções e somente um trabalho desenvolvido com a Comunidade Escolar (professores, gestores, estudantes e famílias).

Com relação aos níveis de ensino, os dados mostram que o EF II (anos finais- $6^{\circ}$ ao $9^{\circ}$ ano) foi o nível de ensino que mais concentrou pesquisas (quinze trabalhos).

As práticas pedagógicas docentes foram as mais recorrentes nos processos investigativos sobre a temática ambiental, identificadas em 21 pesquisas, reafirmando a importância das representações sociais dos educadores sobre a EA (TRAVASSOS, 2004; REIGOTA, 2007; GUIMARÃES, 2015).

Diante das questões levantadas nesta pesquisa, apontamos para uma carência dentro dos Programas de Pós-Graduação de Educação e Ensino sobre a temática ambiental no EF e afirmamos a necessidade da inserção da EA no EF (Educação Básica) como um todo. Entendemos que apesar da quantidade reduzida de trabalhos (29) eles representam o início do processo da inserção da temática neste nível de ensino e buscam abrir espaços para possíveis discussões e reflexão sobre o trabalho com a EA no âmbito escolar.

\section{REFERÊNCIAS}

BARDIN, Laurence. Análise de Conteúdo. Tradução Luís Antero Reto e Augusto Pinheiro. São Paulo: Edições 70, 2011.

BRASIL. Resolução no ${ }^{2}$, de 15 de Junho de 2012, que estabelece as Diretrizes Curriculares Nacionais para a Educação Ambiental. Diário Oficial da União no ${ }^{\circ} 16$. Brasília, DF, de 18 jun. 2012. Seção 1, p. 70-71.

BRASIL. Lei n. 9795 - 27 de abril de 1999. Dispõe sobre a Educação Ambiental. Política Nacional de Educação Ambiental. Brasília, DF, 1999.

BRASIL. Secretaria de Educação Fundamental. Parâmetros Curriculares Nacionais: Meio Ambiente. Secretaria de Educação Fundamental. Brasília, DF, MEC/SEF, 1998.

BRASIL. Secretaria de Educação Fundamental. Parâmetros curriculares nacionais: apresentação dos temas transversais, ética. Secretaria de Educação Fundamental. Brasília: MEC/SEF, 1997.

BRASIL. Constituição da República Federativa do Brasil de 1988. Brasília, DF, 1988. 
Ensino, Saúde e Ambiente - V12 (2), pp. 70-87, Ago. 2019

CARVALHO, Luiz Marcelo de. A temática ambiental e a escola de $\mathbf{1}^{\circ}$ grau. 1989, $282 \mathrm{f}$.

Tese (Doutorado)-Faculdade de Educação, Universidade de São Paulo, São Paulo, 1989.

DIAS, Genebaldo. A situação da educação ambiental no Brasil é fractal. In: Panorama da Educação Ambiental no Ensino Fundamental. Brasília, MEC; SEF, 149 p., 2001.

DIAS, Genebaldo. Educação Ambiental: Princípios e Práticas. 9. ed. São Paulo: Gaia, 2010.

DIAS, Carolina Mandarini. Práticas Pedagógicas de Educação Ambiental em Áreas Protegidas: um estudo a partir de dissertações e teses (1981-2009). 2015. 208f. Tese (Doutorado em Ensino de Ciências e Matemática), Universidade Estadual de Campinas, Campinas. 2015.

FERREIRA, Norma Sandra de Almeida. As Pesquisas denominadas "Estado da Arte". Revista Educação \& Sociedade. v. 23, n.79, pp.257-272, 2002. Disponível em http://www.scielo.br/pdf/es/v23n79/10857.pdf.. Acessado em 27 outubro de 2017.

GUERRA, Antonio Fernando S. Ambientalização e Sustentabilidade nas Universidades: subsídios, reflexões e aprendizagens. Itajaí. Ed. Univali. 2015. In: GUERRA, Antonio Fernando Silveira; FIGUEIREDO, Mara Lúcia; ORSI, Raquel Fabiane Mafra; STEUCK, Eliane Renata; CARLETTO, Denise Lemke; SILVA, Marcia Pereira da; LUNA, José Marcelo Freitas de. (Org.). A ambientalização na Educação Superior: trajetória e perspectivas. São Carlos, SP: EESC/USP, p. 10-33, 2015.

GUIMARÃES, Mauro. A Dimensão Ambiental na Educação. Campinas, SP: Papirus, 2015.

LOUREIRO, Carlos Frederico Bernardo. Educação ambiental e movimentos sociais na construção da cidadania ecológica e planetária. In: LOUREIRO, C. F. B.; LAYRARGUES, P. P; CASTRO, R. S. (Org.). Educação ambiental: repensando o espaço da cidadania. 5. ed. São Paulo: Cortez. v. 249, p. 73-104, 2011.

MEGID NETO, Jorge. Educação Ambiental como campo de conhecimento: a contribuição das pesquisas acadêmicas para sua consolidação no Brasil. Revista Pesquisa em Educação Ambiental, Ribeirão Preto. v. 4, n. 2, p. 95-110, 2009.

NOGUEIRA, Marilac Luiza de Souza Leite Sousa. Práticas Interdisciplinares em Educação Ambiental na Educação Básica: o que nos revelam as pesquisas acadêmicas brasileiras (1981 - 2012). Tese (Doutorado em Educação), Universidade Estadual de Campinas - UNICAMP. Campinas, SP, 2016.

PENTEADO, Heloisa Duplas. Meio ambiente e formação de professores. 3. ed. São Paulo: Cortez, 120 p., 2000.

REIGOTA, Marcos. O Estado da Arte da Pesquisa em Educação Ambiental no Brasil. Revista Pesquisa em Educação Ambiental, Ribeirão Preto. v.2, p.33-66, 2007.

REIGOTA, Marcos. O que é educação ambiental. São Paulo: Brasiliense, 2015.

ROMANOWSKI, Joana Paulin; ENS, Romilda Teodora. As pesquisas denominadas do tipo "estado da arte" em educação. Revista Diálogo Educacional, Curitiba, v.6, n.19, p.37-50, set/dez., 2006. 
SATO, Michèle. Debatendo os desafios da educação ambiental. Revista Eletrônica do Mestrado em Educação Ambiental, Rio Grande: Universidade Federal do Rio Grande; FURG. v. 1, p. 14-33, 2001. Disponível em:

http://nead.uesc.br/arquivos/Biologia/bsc1/artigo1_Debatendo_os_desafios_da_ed_ambiental. pdf.. Acessado em 28 outubro de 2017.

SAUVÉ, Lucie. Uma cartografia das correntes em educação ambiental. In: SATO, Michele, CARVALHO, Isabel C. Moura. (Orgs.). Educação Ambiental. Porto Alegre: Artmed, 2005, p.17-44.

SAUVÉ, Lucie. Educação Ambiental e desenvolvimento sustentável: uma análise complexa. Educação Pública, Cuiabá, v. 6, n. 10, jul./dez. 1997. Disponível em: http://www.ufmt.br/revista/arquivo/rev10/educacao_ambiental_e_desenvolvim.html. Acessado em 25 de outubro de 2017.

TRAVASSOS, Edson Gomes. A prática da educação ambiental nas escolas. Porto Alegre: Mediação, 2004.

TOZONI-REIS, Marília Freitas de Campos. Temas Ambientais como 'temas geradores': contribuições para uma metodologia educativa ambiental crítica, transformadora e emancipatória. Educar em Revista, Curitiba - PR. v. 27, p. 93-110, 2006. 